\title{
Management of spinal meningiomas: surgical results and a review of the literature
}

\author{
Matthias Setzer, M.D., ${ }^{1}$ Hartmut Vatter, M.D., ${ }^{1}$ Gerhard Marquardt, M.D. ${ }^{1}$ \\ Volker Seifert, M.D., ${ }^{1}$ ANd Frank D. VRionis, M.D., Ph.D. ${ }^{2}$ \\ ${ }^{\prime}$ Neurosurgical Clinic, Neurocenter, Johann Wolfgang Goethe University, Frankfurt am Main, \\ Germany; and ${ }^{2}$ Neuro-Oncology Program and Department of Neurosurgery, H. Lee Moffitt Cancer \\ Center and Research Institute, University of South Florida College of Medicine, Tampa, Florida
}

\begin{abstract}
Object. In this report, the authors describe their experience in the surgical management of spinal meningiomas at two neurosurgical centers. The results of a literature review are also presented.

Methods. Eighty consecutive patients ( 22 men and 58 women) with spinal meningiomas who had undergone an operation at two specific neurosurgical centers were included in this study. Functional outcomes were evaluated using univariate and multivariate analyses. A review of the literature yielded an additional 651 patients with spinal meningiomas from 9 large studies.

Results. On multivariate analysis, the variable of a poor preoperative neurological state $(\mathrm{p}<0.02$, odds ratio $[\mathrm{OR}]$ 13.6, 95\% confidence interval [CI] 2.6-71.4) and invasion of the arachnoid/pia mater $(\mathrm{p}<0.03, \mathrm{OR} 15.2$, 95\% CI 2.5-90.4) were independent predictors of a poor outcome, whereas invasion of the arachnoid/pia $(\mathrm{p}<0.02$, OR 8.9, 95\% CI 2.2-35) and duration of symptoms ( $\mathrm{p}<0.001$, OR 1.12/month, 95\% CI 1.05-1.2) predicted no improvement (stable or deteriorated condition). The Cox proportional hazards regression analysis showed three significant predictor variables for recurrence: invasion of the arachnoid/pia $(\mathrm{p}<0.05$; hazard ratio [HR] 1.8, 95\% CI 1.2-3.6), Simpson resection grade ( $\mathrm{p}<0.012$, HR 6.8, 95\% CI 1.5-3.0), and histological tumor grade (Grade I; $\mathrm{p}<0.001$, HR 0.001-0.17).

Conclusions. Because of the excellent outcome of surgery for benign spinal meningiomas and the association between duration of symptoms and neurological compromise with a poor functional outcome, early operation is the treatment of choice. In cases of malignant transformation, adjuvant therapies must be considered.
\end{abstract}

(DOI: 10.3171/FOC-07/10/E14)

KEY WORDS • functional outcome • recurrence • spinal cord meningioma

$\mathrm{M}$ ENINGIOMAS are typically benign, slowly growing tumors. Despite the fact that their histogenesis is unclear, it is thought that arachnoidal cells are the most likely origin of these lesions. ${ }^{20}$ Meningiomas account for 13 to $19 \%$ of all intracranial tumors. ${ }^{35,45}$ Spinal meningiomas represent $12 \%$ of all meningiomas ${ }^{31}$ and 25 to $45 \%$ of intradural spine tumors. ${ }^{14}$ Spinal meningiomas lead to chronic spinal cord compression and myelopathy. Treatment is predominantly surgical. Previously published data indicate mostly favorable outcomes; however, progressive spinal cord compression due to a spinal meningioma can lead to neurological deterioration that, at times, can result in a permanent deficit even after successful surgery.11,13,16, $18,21,26,28,30,39$

In this article we review our experience at two neurosurgical centers with the surgical management of spinal me-

Abbreviations used in this paper: $\mathrm{CI}=$ confidence interval; $\mathrm{CSF}=$ cerebrospinal fluid; $\mathrm{HR}=$ hazard ratio; $\mathrm{MEP}=$ motor evoked potential; $\mathrm{MR}=$ magnetic resonance; $\mathrm{OR}=$ odds ratio; $\mathrm{SSEP}=$ somatosensory evoked potential. ningiomas with particular attention given to surgical techniques, adjuvant therapies, prognostic factors, recurrence rates, and long-term outcomes. Furthermore, we reviewed the literature as it pertains to the surgical treatment of these tumors.

\section{Clinical Material and Methods}

\section{Patient Population}

This study included 80 consecutive patients ( 22 men and 58 women) with spinal meningiomas who had undergone an operation between June 1, 1999, and June 1, 2007, at the Neurosurgical Clinic of Johann Wolfgang Goethe University, Frankfurt, and the H. Lee Moffitt Cancer Center of the University of South Florida, Tampa. Given that the scope of the our review is spinal meningiomas, only those tumors with a location below the foramen magnum were considered. Craniocervical meningiomas with intracranial extension and anterior foramen magnum meningiomas were excluded as they represent entities other than upper cervical spinal meningiomas. ${ }^{2,33}$ 


\section{Neurological and Neuroradiological Assessment}

Patients were neurologically examined preoperatively, postoperatively at discharge, and at 6 months postoperatively, and at a later follow-up. Neurological examination included scoring of sensory deficits, pain, dysesthesias, motor weakness, gait ataxia, bladder function, and bowel function. We adopted the overall functional neurological classification scheme of McCormick et al. ${ }^{22}$ (Table 1), which was originally developed for intramedullary ependymomas. Magnetic resonance imaging was performed within 72 hours before surgery and at 6 months postoperatively. Depending on the histological grade of the tumor, follow-up MR imaging studies were conducted in 1-year or more intervals.

\section{Surgical Procedures}

Indications for surgery included spinal cord compression, neurological signs, and pain. On the day of admission to the hospital, the oral or intravenous administration of dexamethasone was started and continued for 3 to 5 days postoperatively. Decompression of the spinal cord was the primary goal of surgery. Depending on the rate and degree of neurological compromise, the operation was performed in an emergency or elective manner. Somatosensory evoked potentials and MEPs were routinely monitored in each of the patients. Patients with malignant meningiomas underwent external-beam radiation therapy alone or in combination with chemotherapy after surgery.

\section{Clinical and Radiological Variables}

Clinical variables considered for analysis were as follows: age (in years), duration of symptoms (in months), preoperative neurological state (McCormick grade on admission), functional outcome (McCormick grade at the end of the follow-up), neurological outcome (improved, stable, or deteriorated/patient dead), surgical approach, extent of resection (according to Simpson ${ }^{37}$ ), invasion of the arachnoid/pia mater and nerve root involvement, tumor type and grade, recurrence, number and type of complications, and

TABLE 1

Clinical/functional classification scheme for patients harboring spinal meningiomas*

\begin{tabular}{|c|c|}
\hline Grade & Definition \\
\hline I & $\begin{array}{l}\text { neurologically normal; mild focal deficit not significant- } \\
\text { ly affecting function of involved limb; mild spasticity } \\
\text { or reflex abnormality; normal gait }\end{array}$ \\
\hline II & $\begin{array}{l}\text { presence of sensorimotor deficit affecting function of } \\
\text { involved limb; mild to moderate gait difficulty; severe } \\
\text { pain or dysesthetic syndrome impairing patient's } \\
\text { quality of life; still functions and ambulates indepen- } \\
\text { dently }\end{array}$ \\
\hline III & $\begin{array}{l}\text { more severe neurological deficit; requires cane/brace for } \\
\text { ambulation or significant bilat upper extremity impair- } \\
\text { ment; may or may not function independently }\end{array}$ \\
\hline IV & $\begin{array}{l}\text { severe deficit; requires wheelchair or cane/brace w/ bilat } \\
\text { upper extremity impairment; usually not independent }\end{array}$ \\
\hline
\end{tabular}

* For the present study patients without symptoms and neurological deficits had a Grade 0 . Table reprinted with permission from McCormack et al: J Neurosurg 72:523-532, 1990. adjuvant therapies. Neuroimaging variables that were evaluated included tumor location, cord edema, extent of spinal cord compression, site of dural attachment, and calcification. Histological grades refer to the World Health Organization classification of meningiomas.

\section{Statistical Analysis}

Statistical procedures were performed using a commercially available software package (SPSS, version 12.0, SPSS, Inc.). Categorical variables were analyzed using the chi-square test, continuous data with the Mann-Whitney U-test, and comparisons of multiple groups with the H-test of Kruskal-Wallis. Univariate analysis was performed to determine the effect of clinical and neuroimaging variables on long-term outcome. In a second step, a multivariate analysis was performed to find independent predictors of long-term outcome after surgical treatment of intraspinal meningiomas by using a backward stepwise binary logistic regression analysis. For this step, the dependent variables of functional outcome and neurological outcome were dichotomized. Variables with significant probability values on univariate analyses were considered as potentially independent on multivariate analysis.

The time-dependent variable of survival was analyzed using the Kaplan-Meier method to estimate the median survival time. The Cox regression was used to find predictive factors for the variable of recurrence, after first identifying potential predictors on univariate analysis. A backward stepwise method was used to construct multivariate models for both logistic and Cox regressions in relation to various dependent variables and with the inclusion criterion of a probability value less than 0.05 . Continuous variables are expressed as the means \pm standard deviation.

\section{Literature Review}

Search Strategy. A MEDLINE database search was performed with the following key words: "spinal meningioma," "spinal cord meningioma," "outcome," and "recurrence." The last two key words were only searched in combination with the first two key words. The limits included "English" for the language category, "humans" for the study category, and "added to MEDLINE in the last 30 years" for the period of publication. The date of the latest search was June 2007.

Selection Criteria. Clinical papers about the surgical management of spinal meningiomas that included treatment options and an outcome analysis on follow-up were eligible for evaluation. Reference lists in articles were scrutinized for further pertinent material. Articles were included when they contained quantitative data about the outcome and recurrence rate after surgical treatment of spinal meningiomas. Papers focused on spinal schwannomas and meningiomas together were excluded. Articles that did not include the number of patients in the treatment groups were also excluded.

Selection and Analysis of Articles. The selection of papers as well as the evaluation of study quality was performed by two authors who independently reviewed the articles for inclusion and exclusion criteria. Information extracted from eligible studies included the following variables: study design, total number of patients, approach, instrumentation, 
histological features, functional outcome on long-term follow-up, recurrence rate, and adjuvant therapies.

\section{Results}

\section{Institutional Analysis}

Baseline Data. The mean age was $61.9 \pm 16.0$ years (range 20-91 years). The mean follow-up was $43.5 \pm 24.8$ months, and the mean duration of symptoms until surgery was $11.8 \pm 5.3$ months. The patient clinical and radiographic characteristics are summarized in Table 2.

Tumor Resection Grades. Complete resection (Simpson Grades I and II) was achieved in 75 patients (93.8\%), Simpson Grade III was achieved in one patient (1.2\%), and Simpson Grade IV in four patients (5.0\%). The latter two categories were seen exclusively in patients with highgrade tumors.

Complications. Two patients (2.5\%) had a CSF leak, one patient $(1.25 \%)$ had a superficial wound infection, and one patient $(1.25 \%)$ died of pulmonary embolism in the immediate postoperative period. Thus, the overall complication rate was $5 \%$, and the perioperative mortality rate was $1.25 \%$.

Functional Outcome and Neurological Course. After a mean follow-up of $43.5 \pm 24.8$ months, 20 patients $(25 \%)$ were free of symptoms (Grade 0), 31 (38.8\%) had mild focal deficits with no effect on normal function (McCormick Grade I), 14 (17.5\%) had sensorimotor deficits affecting normal function but were still ambulating (McCormick Grade II), eight (10\%) had more severe deficits requiring orthotics (cane or brace) for ambulation (McCormick Grade III), and three (3.75\%) had major sensorimotor deficits and were functionally fully dependent (McCormick Grade IV). Four patients could not be evaluated in terms of functional outcome because they died; one died in the immediate postoperative period due to embolism and 3 patients with high-grade tumors died of tumor progression. At the end of the follow-up, 57 patients $(71.3 \%)$ had improvement, $18(22.5 \%)$ remained stable, and four $(5.0 \%)$ deteriorated or were dead (three of four patients with high-grade tumors died, and one patient with an atypical [Grade II] meningioma clinically deteriorated due to tumor progression).

Univariate Analysis. After dichotomizing the variable of functional outcome (McCormick grade at the end of the follow-up), significant differences were found for the following variables in comparing the good- and poor-outcome groups: en plaque growth $(\mathrm{p}<0.03$, OR $3.9,95 \% \mathrm{CI}$ 1.5-10.1), Simpson resection grade $(\mathrm{p}<0.006$, OR 3.4 , 95\% CI 1.4-8), preoperative McCormick grade ( $\mathrm{p}<$ $0.006)$, and histological tumor grade ( $p<0.012)$. In comparing the dichotomized variable of the neurological state at the end of follow-up (improvement compared with no improvement), significant differences were found for the following variables: invasion of arachnoid/pia mater $(\mathrm{p}<$ 0.029 , OR 2.2, 95\% CI 1.1-4.3), histological tumor grade $(\mathrm{p}<0.047)$, and duration of symptoms $(7.04 \pm 6.5$ months compared with $23.52 \pm 20.9$ months, respectively, $\mathrm{p}<$ $0.01)$. The ORs refer to the bad-outcome group.

Multivariate Analysis. Using a backward stepwise method in a binary logistic regression, the multivariate rela-

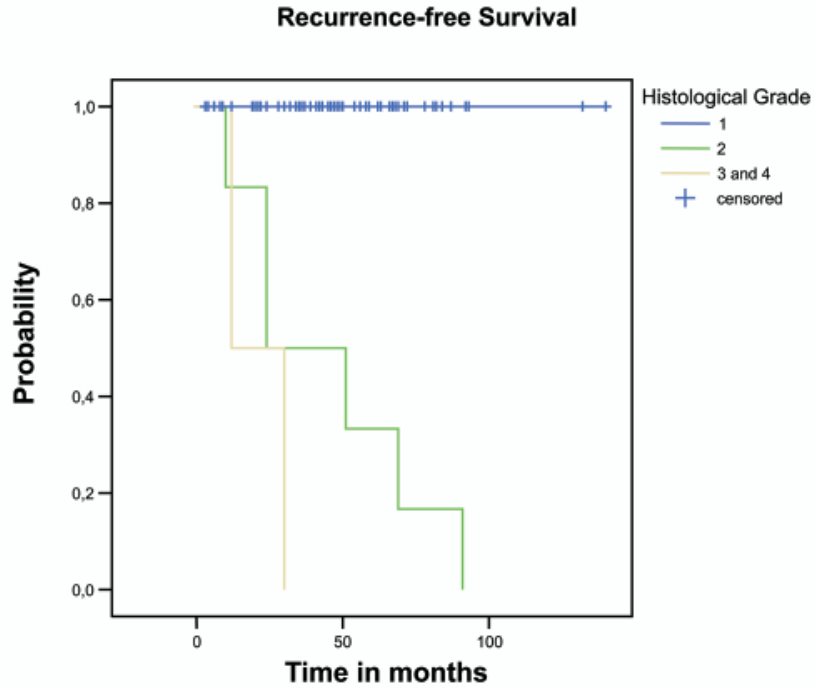

FIG. 1. Probability of recurrence for Grade I, II, and III and IV spinal meningiomas.

tionships were analyzed for the dependent (dichotomized) variables of functional outcome at the end of the follow-up and neurological outcome at the end of the follow-up. Among the risk factors for a bad functional outcome that were significant on univariate analysis, the variables of invasion of arachnoid/pia mater $(\mathrm{p}<0.03$, OR 15.2, 95\% CI 2.5-90.4) and poor preoperative McCormick grade ( $\mathrm{p}<$ 0.02 , OR $13.6,95 \%$ CI 2.6-71.4) remained significant in the multivariate regression model (Nagelkerke R2 $=0.47$ ). For the dichotomized variable of neurological outcome at the end of follow-up, the variables of invasion of arachnoid/pia mater $(\mathrm{p}<0.02$, OR $8.9,95 \%$ CI 2.2-35) and duration of symptoms $(\mathrm{p}<0.001$, OR $1.12 /$ month, $95 \%$ CI 1.05-1.2) were independent predictors for no improvement (stable and deterioration; Nagelkerke R2 $=0.43$ ).

Adjuvant Therapies. Two patients (2.5\%) with high-grade tumors underwent radiotherapy, and one patient $(1.3 \%)$ with a progressive atypical Grade II meningioma underwent stereotactic radiosurgery with a linear accelerator. In one patient, radiotherapy was combined with chemotherapy. In two patients, chemotherapy was administered alone (Table 2). The overall rate of patients treated with adjuvant therapies was $6.25 \%$. These therapies were restricted to patients with high-grade lesions and one progressive lowgrade tumor.

Recurrence and Survival. The overall recurrence rate in this series was $10 \%$. Recurrences were restricted almost exclusively to high-grade meningiomas (four of four patients with high-grade lesions) and atypical meningiomas (three of six patients with atypical Grade II tumors). There was only one recurrence (one in 70 patients) of a Grade I meningioma.

Univariate Analyses. Significant differences between the recurrence and no-recurrence groups were seen for the following variables: Simpson resection grade $(p<0.03)$, invasion of arachnoid/pia mater $(\mathrm{p}<0.001$, OR 36.07 [ORs refer to the recurrence group], 95\% CI 4.8-86.7), his- 
TABLE 2

Summary of characteristics in 80 patients with spinal meningiomas*

\begin{tabular}{|c|c|}
\hline Variable & No. of Patients (\%) \\
\hline \multicolumn{2}{|l|}{ clinical variable } \\
\hline \multicolumn{2}{|l|}{$\operatorname{sex}$} \\
\hline female & $58(72.5)$ \\
\hline male & $22(27.5)$ \\
\hline \multicolumn{2}{|l|}{ manifestation } \\
\hline pain & $36(45.0)$ \\
\hline weakness & $40(50.0)$ \\
\hline sensory deficit & $65(81.3)$ \\
\hline gait ataxia & $46(57.5)$ \\
\hline sphincter dysfunction & $21(26.3)$ \\
\hline \multicolumn{2}{|l|}{ McCormick grade on admission } \\
\hline 0 & $2(2.5)$ \\
\hline I & $28(35.0)$ \\
\hline II & $28(35.0)$ \\
\hline III & $11(13.8)$ \\
\hline IV & $11(13.8)$ \\
\hline \multicolumn{2}{|l|}{ histological grade \& type } \\
\hline \multicolumn{2}{|l|}{ I } \\
\hline meningotheliomatous & $46(57.4)$ \\
\hline psammomatous & $13(16.3)$ \\
\hline transitional & $7(8.8)$ \\
\hline microcystic & $1(1.3)$ \\
\hline chordoid & $1(1.3)$ \\
\hline fibrous & $2(2.5)$ \\
\hline \multicolumn{2}{|l|}{ II } \\
\hline atypical & $6(7.5)$ \\
\hline \multicolumn{2}{|l|}{ III } \\
\hline malignant & $2(2.5)$ \\
\hline \multicolumn{2}{|l|}{ IV } \\
\hline meningosarcoma & $2(2.5)$ \\
\hline \multicolumn{2}{|l|}{ adjuvant therapy } \\
\hline radiotherapy & $1(1.3)$ \\
\hline chemotherapy & $2(2.5)$ \\
\hline combined chemoradiotherapy & $1(1.3)$ \\
\hline stereotactic radiosurgery & $1(1.3)$ \\
\hline lesion recurrence & $8(10.0)$ \\
\hline malignant transformation & $2(2.5)$ \\
\hline \multicolumn{2}{|l|}{ McCormick grade at end of FU } \\
\hline 0 & $20(25.0)$ \\
\hline I & $31(38.8)$ \\
\hline II & $14(17.5)$ \\
\hline III & $8(10.0)$ \\
\hline IV & $3(3.75)$ \\
\hline \multicolumn{2}{|l|}{ neurological state at end of FU } \\
\hline improved & $57(71.3)$ \\
\hline stable & $18(18.8)$ \\
\hline deteriorated/dead & $5(6.2)$ \\
\hline \\
\hline & $17(21.3)$ \\
\hline cervicothoracic & $6(7.5)$ \\
\hline thoracic & $48(60.0)$ \\
\hline thoracolumbar & $6(7.5)$ \\
\hline lumbar & $3(3.8)$ \\
\hline \multicolumn{2}{|l|}{ extent of spinal cord compression } \\
\hline spinal cord shell like compressed & $23(28.8)$ \\
\hline tumor extension $>50 \%$ of spinal canal & $34(42.5)$ \\
\hline tumor extension $<50 \%$ of spinal canal & $17(21.3)$ \\
\hline none & $6(7.5)$ \\
\hline \multicolumn{2}{|l|}{ calcification } \\
\hline none & $65(81.3)$ \\
\hline partial & $15(18.8)$ \\
\hline complete & 0 \\
\hline
\end{tabular}

TABLE 2 (continued)

\begin{tabular}{lc}
\hline \hline $\begin{array}{l}\text { surgical variable } \\
\text { dural attachment } \\
\text { ventral }\end{array}$ \\
$\quad$ ventrolat & $14(17.5)$ \\
lat & $33(41.2)$ \\
$\quad$ dorsolat & $11(13.8)$ \\
$\quad$ dorsal & $17(21.2)$ \\
growth en plaque & $5(6.2)$ \\
extradural tumor extension & $3(3.8)$ \\
surgical approach & $5(6.3)$ \\
dorsal (laminectomy or hemilaminectomy) & \\
dorsolat (costotransversectomy) & $79(98.75)$ \\
instrumentation & $1(1.25)$ \\
Simpson resection grade & $1(1.25)$ \\
I & \\
II & $4(5.0)$ \\
III & $71(88.8)$ \\
IV & $1(1.2)$ \\
complication & $4(5.0)$ \\
CSF fistula & \\
thromboembolism & $2(2.5)$ \\
wound infection & $1(1.3)$ \\
\hline FU follow & $1(1.3)$ \\
\hline
\end{tabular}

tological tumor type $(\mathrm{p}<0.008)$, histological tumor grade $(\mathrm{p}<0.001)$, and patient age $(45.0 \pm 17.8$ years compared with $63.8 \pm 14.7$ years, respectively, $\mathrm{p}<0.006$ ).

Multivariate Analysis. The Cox proportional hazard regression analysis showed three significant predictors of the time-dependent variable of recurrence: invasion of pia mater ( $\mathrm{p}<0.05$, HR 1.8, 95\% CI 1.2-3.6), Simpson resection grade ( $\mathrm{p}<0.012$, HR 6.8, 95\% CI 1.5-3.0), and histological tumor grade (Grade I; $\mathrm{p}<0.001$, HR 0.001-0.17).

Median and Recurrence-Free Survival Times. The median survival in patients with Grade I or II tumors was 243 months; and with Grade III or IV tumors, 25 months. The recurrence-free survival time for patients with Grade III or IV meningiomas was 12 months; for Grade II meningiomas, 91 months; and for Grade I meningiomas, 132 months ( $<<0.001$, log-rank test) (Fig. 1).

\section{Literature Review}

Baseline Data. The MEDLINE review yielded nine large studies ${ }^{11,13,16,18,21,26,28,30,39}$ involving 651 patients with spinal meningiomas. The design was retrospective in all nine studies. Information about the surgical approach, histological features, functional outcome on long-term follow-up, recurrence rates, and adjuvant therapies are listed in Table 3 . The results provided by our institutional analysis were added to the data from the nine studies that fulfilled the inclusion criteria for the literature review.

Functional Outcome. To enhance the comparison between the studies, we evaluated the rate of patients with a benefit from the operative procedure. A benefit was attained if at the last follow-up the patient was neurologically intact or had improved compared with the preoperative state. The mean benefit rate was $88.6 \pm 4.3 \%$ (range 85-95\%).

Complication and Recurrence Rates. The mean operative mortality rate was $2.1 \pm 3.3 \%$ (range $0-3.4 \%$ ); the mean 
TABLE 3

Literature review of studies on spinal meningiomas*

\begin{tabular}{|c|c|c|c|c|c|c|c|c|}
\hline Authors \& Year & $\begin{array}{l}\text { Study Design \& } \\
\text { Statistical analysis }\end{array}$ & $\begin{array}{l}\text { No. of } \\
\text { Pa- } \\
\text { tients }\end{array}$ & $\begin{array}{l}\text { Surgical } \\
\text { Approach }\end{array}$ & $\begin{array}{l}\% \text { Com- } \\
\text { plete } \\
\text { Resec- } \\
\text { tions }\end{array}$ & $\begin{array}{l}\text { Operative } \\
\text { Morbidity } \\
\text { Rate }\end{array}$ & $\begin{array}{c}\text { Operative } \\
\text { Mortality } \\
\text { Rate }\end{array}$ & $\begin{array}{l}\% \text { Patients w/ } \\
\text { Late Outcome } \\
\text { of Improved } \\
\text { or Intact }\end{array}$ & $\begin{array}{l}\text { Recur- } \\
\text { rence } \\
\text { Rate }\end{array}$ \\
\hline Levy et al., 1982 & $\begin{array}{c}\text { retrospective \& } \\
\text { descriptive }\end{array}$ & 97 & dorsal & 82 & 15.4 & 1.0 & 85 & 3.1 \\
\hline $\begin{array}{l}\text { Namer et al., } \\
1987\end{array}$ & $\begin{array}{c}\text { retrospective \& } \\
\text { descriptive }\end{array}$ & 29 & dorsal & 93 & 24.1 & 3.4 & 86.2 & NA \\
\hline $\begin{array}{l}\text { Solero et al., } \\
1989\end{array}$ & $\begin{array}{c}\text { retrospective \& } \\
\text { descriptive }\end{array}$ & 174 & dorsal $\dagger$ & 97 & 1 & 1.1 & 85.7 & 6.4 \\
\hline Roux et al., 1996 & $\begin{array}{c}\text { retrospective \& } \\
\text { descriptive }\end{array}$ & 54 & dorsal $\dagger$ & 93 & 5.5 & 0 & 85 & 3.7 \\
\hline King et al., 1998 & $\begin{array}{c}\text { retrospective \& } \\
\text { descriptive }\end{array}$ & 78 & dorsal & 99 & 1 & 1 & 95 & 1.3 \\
\hline $\begin{array}{l}\text { Klekamp \& } \\
\text { Samii, } 1999\end{array}$ & $\begin{array}{c}\text { retrospective \& } \\
\text { univariate }\end{array}$ & 117 & dorsal & 89 & 11.1 & 1.7 & $\mathrm{NA}$ & 14.7 \\
\hline $\begin{array}{l}\text { Gezen et al., } \\
2000\end{array}$ & $\begin{array}{c}\text { retrospective \& } \\
\text { descriptive }\end{array}$ & 36 & dorsal $\dagger$ & 97 & 3 & 3 & 86.1 & 5.5 \\
\hline $\begin{array}{l}\text { Gottfried et al., } \\
2003\end{array}$ & $\begin{array}{l}\text { retrospective \& } \\
\text { descriptive }\end{array}$ & 25 & dorsal $\dagger$ & 92 & 0 & 0 & 92 & 4.0 \\
\hline Peker et al., 2005 & $\begin{array}{l}\text { retrospective \& } \\
\text { descriptive }\end{array}$ & 41 & dorsal & 98 & 9.7 & 0 & 94 & 0 \\
\hline present study & $\begin{array}{l}\text { retrospective \& } \\
\quad \text { uni- \& multi- } \\
\text { variate }\end{array}$ & 80 & dorsal $\dagger$ & 95 & 5.0 & 1.2 & 93.5 & 10 \\
\hline
\end{tabular}

$* \mathrm{NA}=$ not available

$\dagger$ With lateral extension when necessary.

operative morbidity rate was $6.2 \pm 8.1 \%$ (range $0-24.1 \%$ ). The most common cause of surgery-related death was pulmonary embolism; and of operative morbidity, a CSF leak.

The mean overall recurrence rate among the reviewed studies was $4.7 \pm 4.3 \%$ (range $0-14.7 \%$ ).

\section{Illustrative Cases}

\section{Case 1}

History and Examination. This 42-year-old woman was first seen in October 1999, with a 2-month history of progressive leg weakness and intermittent bladder dysfunction. The neurological examination revealed a 3/5 paraparesis and bilateral hyperreflexia of the legs with a bilateral Babinski sign. There was a sensory deficit below the T- 8 level as well as severe ataxia. The patient could not stand or walk. Magnetic resonance imaging showed a large, contrast-enhancing, intradural extramedullary tumor with nearly complete filling of the spinal canal and displacement of the spinal cord (Fig. 2).

Operation. With the patient in a prone position, during MEP and SSEP monitoring, a T-7 laminectomy was performed. The dura mater was opened, and the tumor was exposed. There was no pial invasion, and a clear plane between the spinal cord and tumor could be created. After internal debulking of the lesion with an ultrasonic aspirator, the tumor was then mobilized and totally resected. The dural attachment was found ventrolaterally and was coagulated. A histopathological examination revealed central tumor calcification, which could also be seen on MR imaging (Fig. 2 left).
Postoperative Course. A postoperative MR image showed complete tumor resection without any evidence of residual lesion or spinal cord signal alterations. The patient recovered progressively and was discharged after a 7-day hospital stay and a 3-week stay in the rehabilitation unit. At the last follow-up examination 6 years and 9 months after the operation, there was no evidence of tumor recurrence on MR imaging. The paraparesis and gait ataxia receded completely, and the patient regained full bladder control.

\section{Case 2}

History and Examination. This 36-year-old man presented with a 2-year history of upper back pain and a 6-month history of gait disturbances. Two days before admission, he lost his ability to walk. A neurological examination revealed a kyphotic deformity of the thoracic spine and a $3 / 5$ paraparesis with bilateral hyperreflexia and a positive $\mathrm{Ba}-$ binski sign on both sides. Response to pinprick sensation was present below the T-2 level. Bowel and bladder function were both normal. Magnetic resonance imaging of the cervicothoracic spine showed a contrast-enhancing tumor from T-1 to T-4 with compression of the spinal cord, extension to the paravertebral muscles, and local destruction of the T-3 vertebra. The tumor caused severe deformity with kyphosis at T3-4 (Fig. 3A and B).

Operation. Tumor removal was performed in three steps. During the first operation, an emergency laminectomy of T1-4 was performed, and the spinal cord was decompressed. The lesion had a tough consistency and was located both extra- and intradurally. After removing the extradural part, the dura was opened, and the intradural lesion 


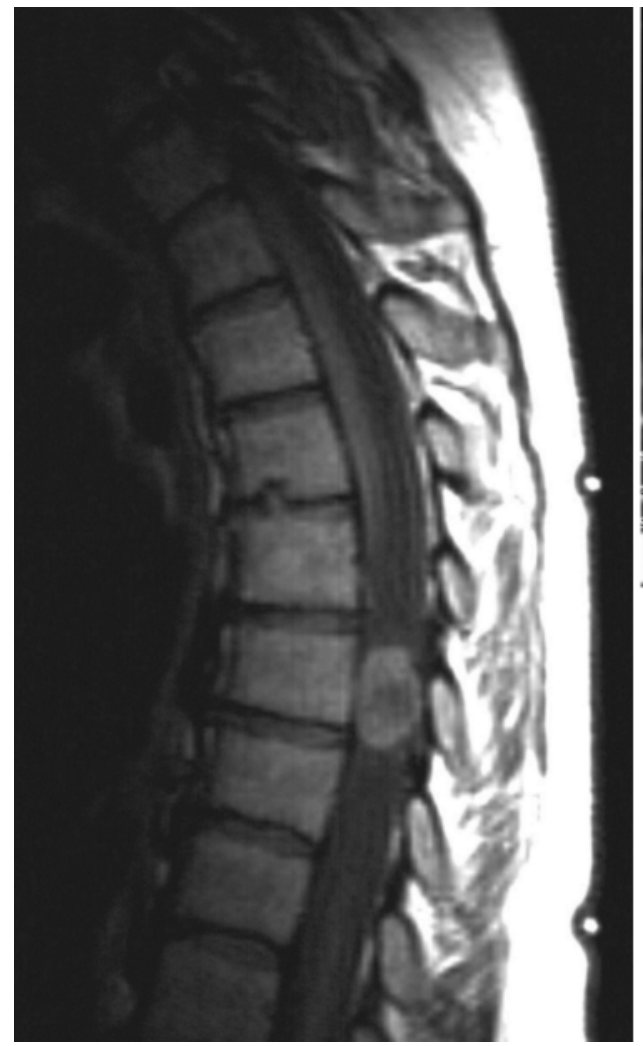

was removed with the aid of an ultrasound aspirator. A plane between the tumor and the spinal cord could be created because pial infiltration was not seen, thus suggesting a low-grade process. In a second operation, a vertebrectomy of T-3 and partially of T-4 was performed using an anterolateral transthoracic approach with implantation of an anterior distraction device (Ulrich Medical) and a ventral Caspar plate (Aesculap) from T-2 to T-4 (Fig. 3C). In a third step, a posterior reconstruction was performed with a CerviFix System (Synthes, Inc.) using lateral mass screws at C-5 and C-6 and pedicle screws from T- 1 to T-6 on both sides. The histological analysis revealed an atypical meningioma Grade II. No adjuvant therapy was given.

Postoperative Course. The postoperative course was uneventful. After a hospital stay of 4 weeks and an additional 3-week stay in rehabilitation, the patient was discharged home. Postoperative MR imaging showed tumor remaining in the intervertebral foramen at T3-4 on the right side. At the last follow-up visit 49 months after the operation, an MR image showed the residual tumor without a significant increase in size. The paraparesis had receded completely, and the patient exhibited only residual sensory loss on the right chest wall.

\section{Case 3}

History and Examination. This 22-year-old woman had a 2 -month history of radiating pain in both arms. A neurological examination revealed no motor or sensory deficits. Magnetic resonance imaging showed a large, contrastenhancing, bilateral paravertebral tumor at the cervicothoracic junction with extension into the intervertebral foramen at C-7 and T-1 on the right side (Fig. 4A and B).

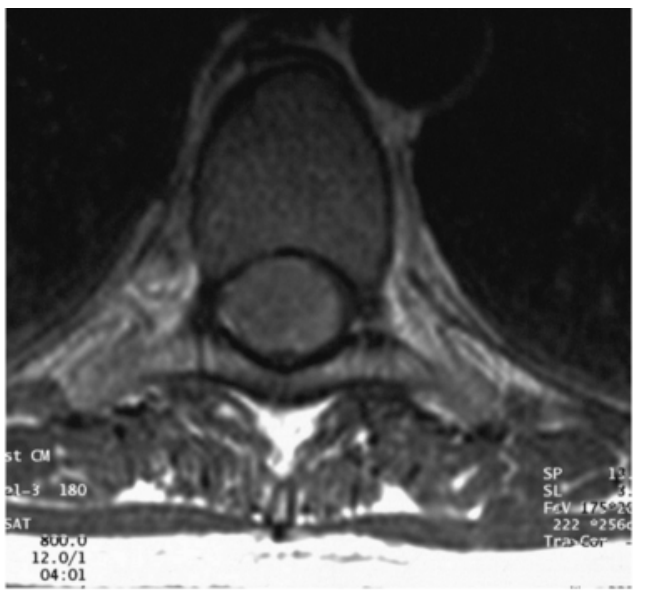

Fig. 2. Case 1. Left: Sagittal T1-weighted MR image of the thoracic spine showing a contrast-enhancing intradural extramedullary tumor at T-7. Note the central hypointense area suggestive of calcification. Right: Axial T1-weighted MR image obtained at the T-7 level, revealing a contrast-enhancing tumor with extensive spinal cord displacement and compression and nearly complete filling of the spinal canal.

Operation. With the patient in a prone position, a right hemilaminectomy at C-7, T-1, and T-2 was performed, and the paravertebral and intraspinal tumor parts were grosstotally resected. The histological diagnosis was malignant meningioma Grade III.

Postoperative Course. The first postoperative MR image confirmed gross-total resection. The patient was then treated with fractionated external-beam radiotherapy (54 Gy). The pain symptoms resolved completely.

Nine months postsurgery, the patient again experienced neck pain. A new MR image demonstrated a recurrent tumor above the former lesion area, reaching from $\mathrm{C}-5$ to the skull base. The irradiated area was tumor free (Fig. 4C-E). In a second operation, the recurrent tumor was resected subtotally and thereafter irradiated with $48 \mathrm{~Gy}$. Thirteen months after the first operation, a third recurrent tumor was diagnosed in the region of the primary tumor at C- 6 and C7 with paravertebral dorsolateral and ventrolateral extension. The lower part of the tumor extended into the upper thoracic cavity. Chemotherapy with ifosfamide and doxorubicin was started. After initial stabilization, the patient died 24 months from the first operation because of tumor progression.

\section{Discussion}

\section{Epidemiological Features}

The exact incidence of spinal meningiomas is not known; however, the total incidence of spinal intradural tumors is estimated to be from 3 to 10 per 100,000 persons per year, ${ }^{38}$ with two thirds of the tumors being extramedullary. Our estimates from a hospital-based population 

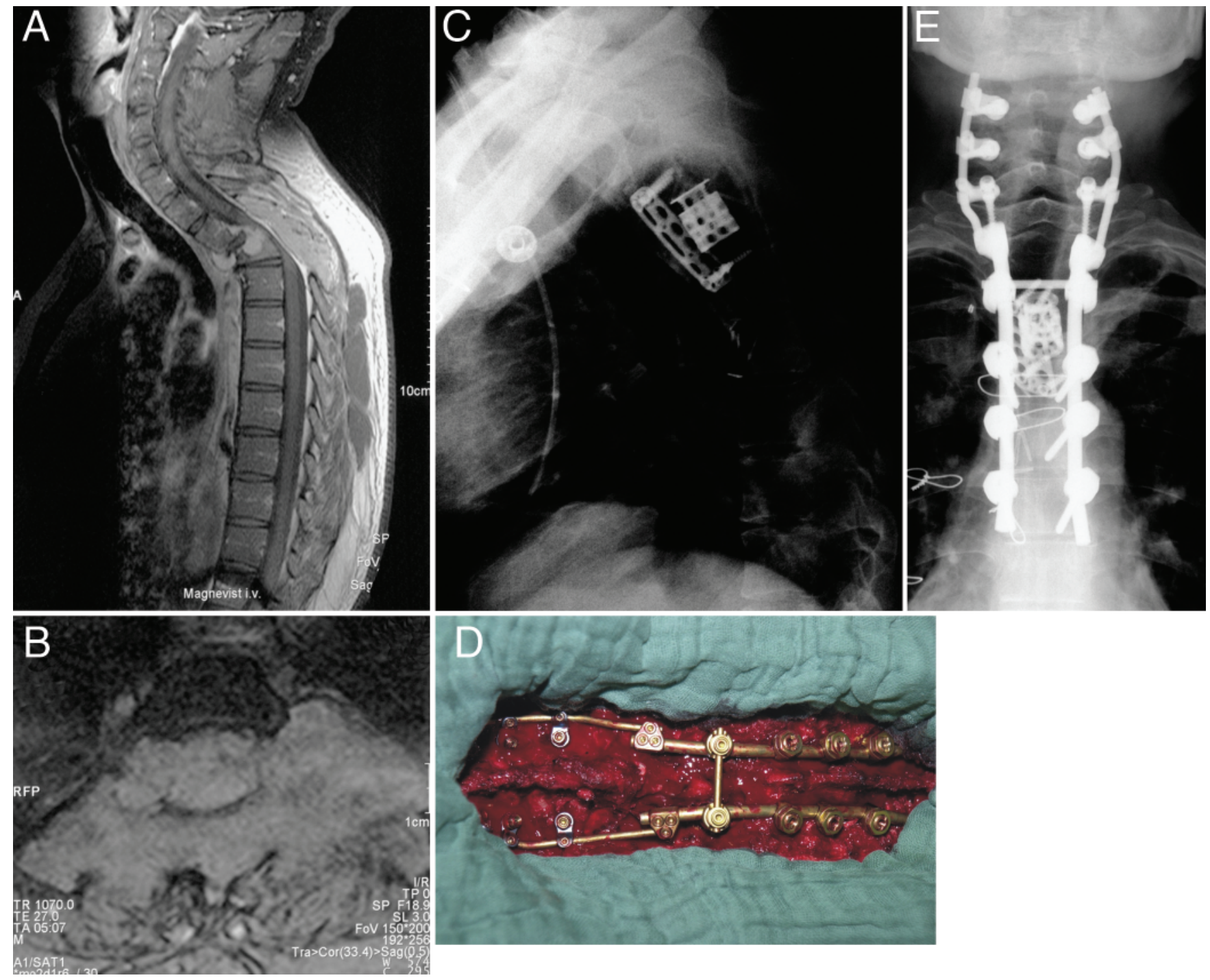

FIG. 3. Case 2. Sagittal Gd-enhanced T1-weighted MR image (A) demonstrating an enhancing tumor from T-1 to T4 with destruction of the T-3 vertebra and hyperkyphosis in the segment T3-4. Axial MR image (B) obtained at the T-3 level, revealing complete filling of the spinal canal and lateral extension into the paravertebral muscles. Delineation of the spinal cord from the tumor is difficult. Lateral x-ray film (C) obtained after a T-3 vertebrectomy, tumor resection, and anterior stabilization with an anterior distraction device and anterolateral plating. Intraoperative photograph (D) and anteroposterior X-ray film (E) showing posterior reconstruction with a CerviFix system and lateral mass screws in C-5 and C-6 and a USS System using pedicle screws from T-1 to T-6.

showed an incidence of meningiomas varying from 0.5 to 2 per 100,000 persons per year. Of course, one must keep in mind that these lesions are slow growing and that their diagnosis often takes considerable time. Therefore, the true incidence is presumably higher. The peak incidence is found between the sixth and eighth decades of life. ${ }^{11,13,16,18,21,26,28,30,39}$ In the present series, most tumors occurred in the seventh decade, which corresponds well with data in the reported literature. In the present series, however, there was a significant difference in age between patients with low- and those with high-grade meningiomas; the latter lesion type occurred more often in younger patients. In contrast to other intradural tumors, there is a strong female predominance with a female/male ratio of 3 to $4: 1$ among patients with spinal meningiomas. ${ }^{11,13,16,18 \text {, }}$ $21,26,28,30,39$ In the present series, the female/male ratio was 2.5:1. Furthermore, there are differences between ethnic groups, with the spinal meningioma/intradural nerve sheath tumor ratio being equal (1:1) in Western but not in Asian populations $(1: 4) .^{5}$

\section{Clinical Presentation}

Spinal meningiomas are usually benign, slow-growing tumors with a long clinical history until a diagnosis is made. The mean duration of symptoms in the present series was 11.8 months and correlates well with the time reported 


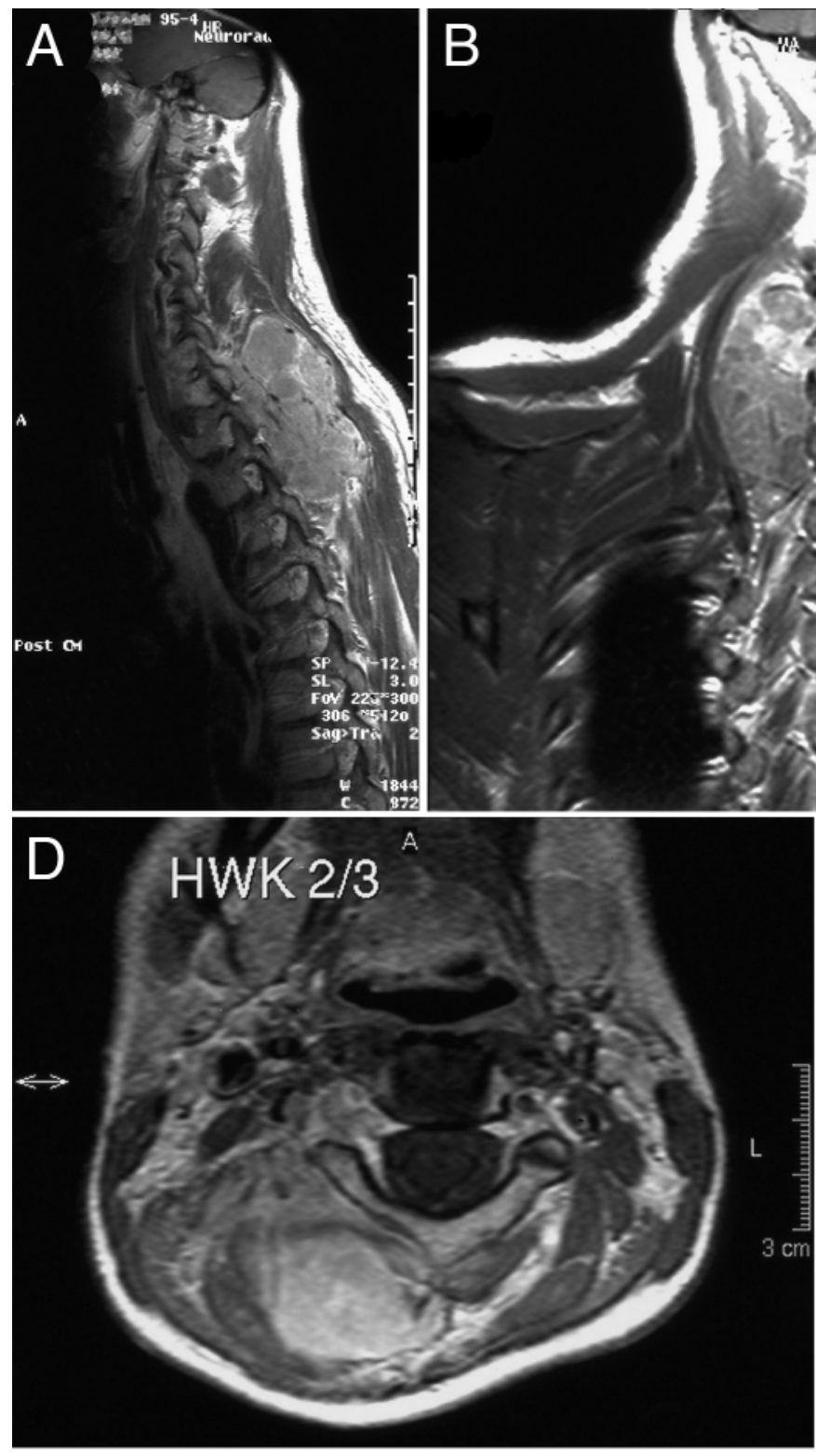

FIG. 4. Case 3. Sagittal (A) and coronal (B) T2-weighted MR images of the cervicothoracic region showing a large contrastenhancing bilateral paravertebral tumor with extension into the intervertebral foramina at C-7 and T-1 on the right side. Sagittal (C), axial (D), and coronal (E) T2-weighted MR images revealing

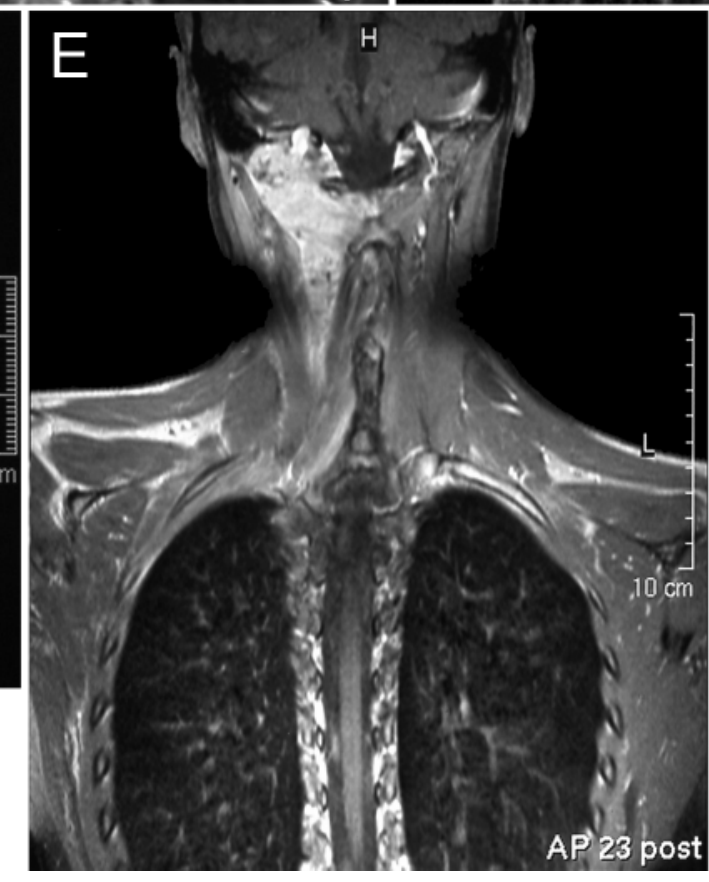
a contrast-enhancing recurrent tumor just above the previous lesion area reaching from $\mathrm{C}-5$ to the skull base.

in the literature (12-24 months). ${ }^{13,16,18,21,30}$ The duration of symptoms in our series was an independent predictor for a lack of improvement after surgery. Clinical symptoms are typically dependent on the tumor location with respect to the spinal cord or nerve roots, the rate of tumor growth, and the extent of spinal cord compression. The most common presenting symptom in this series was a sensory deficit, followed by gait ataxia and weakness. The least common symptom was pain and sphincter dysfunction. The frequency of the presenting symptoms among the reviewed series was quite heterogeneous. ${ }^{11,13,16,18,21,26,28,30,39}$ The introduction and routine use of MR imaging has shortened the time to the diagnosis of a spinal meningioma and therefore has presumably improved outcomes. ${ }^{18}$

\section{Diagnostic Evaluation and Imaging features}

The current standard diagnostic study for a spinal tumor is MR imaging. An MR image provides exact information about tumor localization (affected segment, relation to spinal cord and nerve root, and relation of the tumor to the dura), the extent of spinal cord compression, and further information about the spinal cord and the tumor itself (presence of cord edema and intratumoral signal changes such 
as necrosis, hematoma or calcification) ${ }^{36}$ Spinal meningiomas are usually isointense to the spinal cord (T1- and T2weighted MR images) and show an enhancement after contrast medium (Gd) administration. In limited cases, computed tomography scanning is indicated alone or in addition to MR imaging (contraindications for MR imaging or destruction of osseous structures for better depiction of bone). The main differential diagnosis of spinal meningiomas includes intradural extramedullary schwannomas. There are hints for differentiating one entity from the other (dural tail, broad dural contrast of meningioma, more lateral position of schwannomas, and relation to the nerve root); however, a reliable differentiation between spinal meningiomas and schwannomas is not possible with MR or other imaging techniques.

There is no pathognomonic picture of atypical and invasive spinal meningiomas. On MR images these tumors can enhance as solitary or multiple lesions. The tumor can enhance heterogeneously or in a ringlike fashion. Angiography can reveal a tumor blush with pathological vessels or early venous drainage.

\section{Localization of Spinal Meningiomas}

The most common location of spinal meningiomas is the thoracic spine. In our series we found $60 \%$ thoracic, $13.6 \%$ cervical, 3.8\% lumbar, with the remaining tumors located at the craniocervical, cervicothoracic, and thoracolumbar junctions. The percentage of thoracic spinal meningiomas in the literature review ranged from 64 to $84 \%$, of cervical meningiomas from 14 to $27 \%$, and of lumbar meningiomas from 2 to $14 \%$. $11,13,16,18,21,26,28,30,39$ The site of dural attachment in our series was ventrolateral in $41.2 \%$ of cases, ventral in $7.5 \%$, lateral in $13.8 \%$, dorsolateral in $21.2 \%$, and purely dorsal in $3.8 \%$. Because of the different criteria of previously published studies in describing the relationship of the tumor to the spinal cord, the distribution of the site of tumor origin was heterogeneous in the reviewed studies. ${ }^{11,13,16 \text {, }}$ $18,21,26,28,30,39 \mathrm{We}$ found extradural tumor extension in $6.3 \%$ of the patients in our study; in contrast to other series, ${ }^{16,30,39}$ however, the extension was only partial (the remaining tumor being intradural) in all cases.

\section{Surgical Approach}

The approach should allow wide enough exposure of the tumor and the dural attachment. The most frequent approach has been dorsal, by laminectomy at one level or by hemilaminectomy at one or two levels with lateral extension when necessary (anterior and anterolateral tumors). This standard approach was used in nearly $100 \%$ of the patients in the reviewed studies. ${ }^{11,13,16,18,21,26,28,30,39} \mathrm{In}$ our patients, we have used a ventral approach for tumor resection and subsequent stabilization in only one patient with a large and progressive Grade II lesion (Case 2). In the majority of patients it is possible to resect even large tumors safely and without causing spinal instability by using a standard dorsal or dorsolateral laminectomy approach. In patients with calcified ventral or ventrolateral tumors, a partial vertebrectomy and/or costotransversectomy approach allows safer tumor manipulation and removal. In tumors occurring at the cervicothoracic and/or thoracolumbar junction, dorsal stabilization should be considered to prevent junctional kyphosis.

\section{Tumor Resection}

The primary goal of surgery is complete safe tumor removal and decompression of the spinal cord. Dorsally placed tumors can be removed totally with or without resection of the dural attachment. Anterior lesions should be debulked before dissection of the tumor capsule, exposure of the plane between the tumor and spinal cord, and finally tumor removal. ${ }^{18,23}$ Intraoperative ultrasonography to localize the tumor is recommended by some authors but was not used in our series, in which total tumor resection (Simpson resection Grade I and II) was achieved in $97.2 \%$ of Grade I tumors, $100 \%$ of Grade II tumors, and $33.3 \%$ of Grade III and IV tumors. In previously reported series, the percentages of total resection have ranged from 82 to $99 \%$; however, the percentage of high-grade tumors was lower than in the present series. The dural attachment was coagulated in most cases in the reported studies (15-89\%) including ours, and in only 14 to $57 \%$ of the cases, resection of the dural attachment was performed with suturing of a patch graft. 11,13,16,18,21,26,28,30,39 Some authors prefer to separate the outer and inner layers of the dura and resect the inner layer together with the tumor. ${ }^{32}$ Given the very low recurrence rates, in our opinion, it is not necessary to achieve a Simpson Grade I resection in every Grade I meningioma. In those Grade II to IV, however, a Simpson Grade I resection is crucial to lower recurrence rates and affect survival.

\section{Special Surgical Considerations}

For the majority of spinal meningiomas, the dorsal approach (with partial facetectomy, if necessary) is sufficient to achieve complete tumor resection and prevent spinal instability. However, in rare cases of heavily calcified meningiomas with a ventral or ventrolateral location where internal tumor debulking is not possible via a dorsal approach, it can be safer to perform a partial or complete vertebrectomy for tumor resection along with subsequent instrumentation. ${ }^{9}$ A classification of surgical approaches has been developed to plan the surgical corridor to spinal meningiomas and predict the need for instrumentation. ${ }^{25}$

In invasive and high-grade meningiomas (Cases 2 and 3) with extensive tumor resection, surgery is subject to the principles of modern spinal neoplasm surgery. ${ }^{12,42}$

\section{Patient Complications}

In the reported series, morbidity and mortality rates for spinal meningiomas were low: mean $6.2 \%$ for morbidity and $2.1 \%$ for mortality. The most frequent complications included CSF leak and wound infection, occurring in 0 to $4 \%$ and 0 to $6 \%$, respectively. ${ }^{11,13,16,18,21,26,28,30,39}$ Other, less frequent complications were pulmonary embolism, pneumonia, and myocardial infarction. The major cause of death in the previously published studies was pulmonary embolism. . $11,16,18,21,26,28,30,39^{2}$

\section{Intraoperative Neurophysiological Monitoring}

Electrophysiological monitoring has become a standard procedure in intramedullary tumor surgery. ${ }^{19}$ Motor and sensory pathways can be affected independently both preand postoperatively. ${ }^{40}$ Because there is no correlation between SSEPs and postoperative motor function, it is necessary to monitor both MEPs and SSEPs. ${ }^{44}$ At our institutions, neurophysiological monitoring is performed routine- 
ly in spinal meningioma surgery; among the literature series, the use of neurophysiological monitoring was mentioned in only one. ${ }^{13}$

\section{Histopathological Characteristics}

The most frequent histological types among the Grade I tumors in our and the published series were the meningothelial and psammomatous types. ${ }^{11,13,16,21,26,28,30,39}$ In Grade I meningiomas, there was no correlation between the histo-

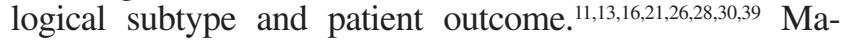
lignant transformation occurred in two $(2.5 \%)$ of 80 patients with spinal meningioma. In our study, we found histological grade to be an independent predictor for tumor recurrence. There were significant differences in the recurrence-free survival times in patients with different histological grades (Fig. 1). There were no data available concerning these issues in the reviewed studies. ${ }^{11,13,16,18,21,26,28,30,39}$ Partial calcification occurred in $18.8 \%$ of the patients in our study. This point is important because calcification complicates the operative procedure and must be considered in the surgical strategy for tumor removal. Note, however, that calcification in our study had no influence on the clinical outcome in patients.

\section{Tumor Recurrence}

Tumor recurrence in Grade I spinal meningiomas is uncommon, and the incidence ranged from 0 to $14.7 \%$ in the reviewed studies. . $^{11,13,16,21,26,28,30,39}$ This rate corresponds well to other series focused on recurrence rates for intradural extramedullary tumors ${ }^{34}$ in particular and for meningiomas in general. ${ }^{24}$ Compared to other locations, the recurrence rate of spinal meningiomas is low. ${ }^{24}$ There are very few patients with Grade II to IV spinal meningiomas included in the reviewed studies, and thus a comparison between tumor grades and recurrence rates of spinal meningiomas is not possible. The total recurrence rate in our study was $10 \%$, with a recurrence rate of $1.4 \%$ for Grade I tumors, 50\% for Grade II lesions, and 100\% for Grade III and IV tumors. In one series the total recurrence rate was $14.7 \%$, which was presumably explained by the inclusion of a greater percentage of Grade II and III meningiomas. ${ }^{18}$ We found a significant difference in age between patients in the recurrence group and those in the no-recurrence group $(45.0 \pm 17.8$ years compared with $63.8 \pm 14.7$ years, respectively). This result correlates well with data from other reports.

\section{Adjuvant Therapies}

Because of the good outcomes and low recurrence rates following surgical therapy, complete tumor resection is the best treatment for spinal meningiomas. In cases of subtotal resection, the efficacy of radiosurgery and stereotactic radiotherapy for intracranial meningiomas with low complication rates has been well established. ${ }^{1,4,6,29,41}$ So far, frame-based stereotactic radiosurgery devices cannot be used to treat tumors below the level of the foramen magnum. The development of frameless radiosurgery techniques has overcome this problem. Preliminary study data have shown that CyberKnife frameless stereotactic radiosurgery is a feasible, safe, and effective treatment for benign spinal lesions, including meningiomas, as a singlefraction therapy. ${ }^{3,10}$ There are limited data about the management of malignant spinal meningiomas. Guidelines inferred from experience with intracranial meningiomas recommend attempting maximal resection followed by fractionated external-beam radiotherapy. If any remaining tumor is well defined on imaging studies, there may be an additional indication for radiosurgery. ${ }^{15}$ The results of chemotherapy for malignant spinal meningiomas have been disappointing; however, there may be a subgroup of recurrent meningiomas for which chemotherapy using hydroxyurea may lead to disease stabilization. ${ }^{43}$

\section{Long-Term Outcome and Prognostic Factors}

Because of the different classifications, $, 17,22,27$ it is difficult to compare results between the previously published studies. To make the series comparable we calculated a benefit rate for the patients who underwent surgery. A good benefit was defined as being neurologically intact or improved at the last follow-up compared with the preoperative status. In the reviewed series this rate ranged from 85 to $95 \%$ (Table 4). In our study we saw no neurological deterioration immediately after surgery. Neurological deficits at the end of the follow-up were remnants of preoperative

TABLE 4

Literature review of studies in terms of histological tumor grades and additive therapies

\begin{tabular}{|c|c|c|c|c|c|c|}
\hline \multirow[b]{2}{*}{ Authors \& Year } & \multicolumn{3}{|c|}{ Percentage of Tumors } & \multicolumn{3}{|c|}{ Percentage of Patients } \\
\hline & Grade II & Grade III & Grade IV & $\begin{array}{c}\text { Stereotactic } \\
\text { Radiosurgery }\end{array}$ & $\begin{array}{l}\text { Radio- } \\
\text { therapy }\end{array}$ & $\begin{array}{l}\text { Chemo- } \\
\text { therapy }\end{array}$ \\
\hline Levy et al., 1982 & 0 & 0 & 0 & 0 & 0 & 0 \\
\hline Namer et al., 1987 & 0 & 0 & 0 & 0 & 0 & 0 \\
\hline Solero et al., 1989 & 0 & 0.5 & 0 & 0 & 0 & 0 \\
\hline Roux et al., 1996 & 0 & 1.8 & 0 & 0 & 3.7 & 0 \\
\hline King et al., 1998 & 0 & 0 & 0 & 0 & 0 & 0 \\
\hline Klekamp \& Samii, 1999 & NA & NA & NA & NA & NA & NA \\
\hline Gezen et al., 2000 & 0 & 0 & 0 & 0 & 5.5 & 0 \\
\hline Gottfried et al., 2003 & NA & NA & NA & NA & NA & NA \\
\hline Peker et al., 2005 & 0 & 0 & 0 & 0 & NA & NA \\
\hline present series & 7.5 & 2.5 & 2.5 & 1.3 & 2.5 & 2.5 \\
\hline
\end{tabular}


deficits. Neurological deterioration was caused by tumor progression.

We found significant predictors of long-term outcome. In a multivariate model, invasion of the arachnoid/pia mater $(\mathrm{p}<0.03$, OR 15.2, 95\% CI 2.5-90.4) and a poor preoperative McCormick grade $(\mathrm{p}<0.02$, OR 13.6, 95\% CI 2.6-71.4) were independent predictors of a poor longterm outcome. Invasion of the arachnoid/pia $(\mathrm{p}<0.02, \mathrm{OR}$ $8.9,95 \%$ CI 2.2-35) and duration of symptoms ( $\mathrm{p}<0.001$, OR 1.12/month, 95\% CI 1.05-1.2) were independent predictors of no improvement after surgery for spinal meningiomas. This result corresponds to other data indicating that infiltration and/or scarring of the arachnoid worsens prognosis. ${ }^{18}$ Because we saw no surgery-related neurological deterioration in our series, we concluded that the increased recurrence rate in the meningioma group with invasion of the arachnoid/pia was the reason for the poor prognosis. In contrast to other studies, dural attachment and ossification in our series were not predictors of a poor outcome. Summing up, the prognosis of benign spinal meningioma treated with complete resection is excellent, with low complication rates and a good long-term functional outcome. ${ }^{11,13,16,21,26,28,30,39}$

\section{Conclusions}

Because of the excellent outcome after surgery for benign spinal meningiomas together with the low complication rates as well as the association between symptom duration and neurological compromise with a poor functional outcome, we recommend early diagnosis and surgery as the treatment of choice. In cases of malignant transformation, adjuvant therapies must be considered.

\section{References}

1. Barami K, Grow A, Brem S, Dagnew E, Sloan AE: Vascular complications after radiosurgery for meningiomas. Neurosurg Focus 22(3):E9, 2007

2. Bassiouni H, Ntoukas V, Asgari S, Sandalcioglu EI, Stolke D, Seifert V: Foramen magnum meningiomas: clinical outcome after microsurgical resection via a posterolateral suboccipital retrocondylar approach. Neurosurgery 59:1177-1187, 2006

3. Bhatnagar AK, Gerszten PC, Ozhasaglu C, Vogel WJ, Kalnicki S, Welch WC, et al: CyberKnife frameless radiosurgery for the treatment of extracranial benign tumors. Technol Cancer Res Treat 4:571-576, 2005

4. Chang SD, Adler JR Jr: Current status and optimal use of radiosurgery. Oncology (Williston Park) 15:209-221, 2001

5. Cheng MK: Spinal cord tumors in the People's Republic of China: a statistical review. Neurosurgery 10:22-24, 1982

6. Chin LS, Szerlip NJ, Regine WF: Stereotactic radiosurgery for meningiomas. Neurosurg Focus 14(5):E6, 2003

7. Cohen-Gadol AA, Zikel OM, Koch CA, Scheithauer BW, Krauss WE: Spinal meningiomas in patients younger than 50 years of age: a 21-year experience. J Neurosurg 98 (3 Suppl): 258-263, 2003

8. Cooper PR, Epstein F: Radical resection of intramedullary spinal cord tumors in adults. Recent experience in 29 patients. J Neurosurg 63:492-499, 1985

9. Freidberg SR: Removal of an ossified ventral thoracic meningioma. Case report. J Neurosurg 37:728-730, 1972

10. Gerszten PC, Ozhasoglu C, Burton SA, Vogel WJ, Atkins BA,
Kalnicki S, et al: CyberKnife frameless single-fraction stereotactic radiosurgery for benign tumors of the spine. Neurosurg Focus 14(5):E16, 2003

11. Gezen F, Kahraman S, Canakci Z, Bedük A: Review of 36 cases of spinal cord meningioma. Spine 25:727-731, 2000

12. Gokaslan ZL, York JE, Walsh GL, McCutcheon IE, Lang FF, Putnam JB, et al: Transthoracic vertebrectomy for metastatic spinal tumors. J Neurosurg 89:599-609, 1998

13. Gottfried ON, Gluf W, Quinones-Hinojosa A, Kan P, Schmidt MH: Spinal meningiomas: surgical management and outcome. Neurosurg Focus 14(6):E2, 2003

14. Helseth A, Mork SJ: Primary intraspinal neoplasms in Norway, 1955 to 1986 . A population-based survey of 467 patients. J Neurosurg 71:842-845, 1989

15. Katz TS, Amdur RJ, Yachnis AT, Mendenhall WM, Morris CG: Pushing the limits of radiotherapy for atypical and malignant meningioma. Am J Clin Oncol 28:70-74, 2005

16. King AT, Sharr MM, Gullan RW, Bartlett LR: Spinal meningiomas: a 20-year review. Br J Neurosurg 12:521-526, 1998

17. Klekamp J, Samii M: Introduction of a score system for the clinical evaluation of patients with spinal processes. Acta Neurochir (Wien) 123:221-223, 1993

18. Klekamp J, Samii M: Surgical results for spinal meningiomas. Surg Neurol 52:552-562, 1999

19. Kothbauer K, Deletis V, Epstein FJ: Intraoperative spinal cord monitoring for intramedullary surgery: an essential adjunct. Pediatr Neurosurg 26:247-254, 1997

20. Lantos PL, Vandenberg SR, Kleihues P: Tumors of the nervous system, in Graham DI, Lantos PL (eds): Greenfield's Neuropathology, ed 6. London: Oxford University Press, 1997, pp 583-879

21. Levy WJ Jr, Bay J, Dohn D: Spinal cord meningioma. J Neurosurg 57:804-812, 1982

22. McCormick PC, Torres R, Post KD, Stein BM: Intramedullary ependymoma of the spinal cord. J Neurosurg 72:523-532, 1990

23. Mimatsu K, Kawakami N, Kato F, Saito H, Sato K: Intraoperative ultrasonography of extramedullary spinal tumors. Neuroradiology 34:440-443, 1992

24. Mirimanoff RO, Dosoretz DE, Linggood RM, Ojemann RG, Lartuza RL: Meningioma: analysis of recurrence and progression following neurosurgical resection. J Neurosurg 62:18-24, 1985

25. Misra SN, Morgan HW: Avoidance of structural pitfalls in spinal meningioma resection. Neurosurg Focus 14(6):E1, 2003

26 Namer IJ, Pamir MN, Benli K, Saglam S, Erbengi A: Spinal meningiomas. Neurochirurgia (Stutt) 30:11-15, 1987

27. Nurick S: The pathogenesis of the spinal cord disorder associated with cervical spondylosis. Brain 95:87-100, 1972

28. Peker S, Cerçi A, Ozgen S, Isik N, Kalelioglu M, Pamir MN: Spinal meningiomas: evaluation of 41 patients. J Neurosurg Sci 49:7-11, 2005

29. Pollock BE: Stereotactic radiosurgery for intracranial meningiomas: indications and results. Neurosurg Focus 14(5):E4, 2003

30. Roux FX, Nataf F, Pinaudeau M, Borne G, Devaux B, Meder JF: Intraspinal meningiomas: review of 54 cases with discussion of poor prognosis factors and modern therapeutic management. Surg Neurol 46:458-464, 1996

31. Russell DS, Rubinstein LJ: Pathology of Tumours of the Nervous System, ed 5. London: Arnold, 1989, pp 449-532

32. Saito T, Arizono T, Maeda T, et al: A novel technique for surgical resection of spinal meningioma. Spine 26:1805-1808, 2001

33. Samii M, Klekamp J, Carvalho G: Surgical results for meningiomas of the craniocervical junction. Neurosurgery 39: 1086-1095, 1996

34. Schick U, Marquardt G, Lorenz R: Recurrence of benign spinal neoplasms. Neurosurg Rev 24:20-25, 2001

35. Schiffer D: Brain Tumors. Pathology and its Biological 
Correlates. Berlin: Springer-Verlag, 1993 pp 283-329

36. Schroth G, Thron A, Guhl L, Voigt K, Niendorf HP, Garces LR: Magnetic resonance imaging of spinal meningiomas and neurinomas. Improvement of imaging by paramagnetic contrast enhancement. J Neurosurg 66:695-700, 1987

37. Simpson D: The recurrence of intracranial meningiomas after surgical treatment. J Neurol Neurosurg Psychiat 20:22-23, 1957

38. Slooff JL, Kernohan JW, MacCarty CS: Primary Intramedullary Tumors of the Spinal Cord and Filum Terminale. Philadelphia: WB Saunders, 1964

39. Solero CL, Fornari M, Giombini S, Lasio G, Oliveri G, Cimino C, et al: Spinal meningiomas: review of 174 operated cases. Neurosurgery 25:153-160, 1989

40. Steinbok P, Cochrane DD, Poskitt K: Intramedullary spinal cord tumors in children. Neurosurg Clin N Am 3:931-945, 1992

41. Torres RC, Frighetto L, De Salles AA, Goss B, Medin P, Solberg $\mathrm{T}$, et al: Radiosurgery and stereotactic radiotherapy for intracranial meningiomas. Neurosurg Focus 4(5):E5, 2003
42. Vrionis FD, Small J: Surgical management of metastatic spinal neoplasms. Neurosurg Focus 15(5):E12, 2003

43. Weston GJ, Martin AJ, Mufti GJ, Strong AJ, Gleeson MJ: Hydroxyurea treatment of meningiomas: a pilot study. Skull Base 16:157-160, 2006

44. Whittle IR, Johnston IH, Besser M: Recording of spinal somatosensory evoked potentials for intraoperative spinal cord monitoring. J Neurosurg 64:601-612, 1986

45. Zülch KJ: Brain Tumors, Their Biology and Pathology, ed 3. Berlin: Springer-Verlag, 1986, pp 357-393

Manuscript submitted July 16, 2007.

Accepted September 12, 2007.

Address correspondence to: Frank D. Vrionis, M.D., M.P.H., Ph.D., H. Lee Moffitt Cancer Center and Research Institute, NeuroOncology Program, University of South Florida College of Medicine, 12902 Magnolia Drive, Tampa, Florida 33612. email: frank.vrionis@moffitt.org. 